\title{
Study the structural and magnetic properties of rare-earth ions (La and Gd) doped $\mathrm{Ba}_{0.9575} \mathrm{Ca}_{0.0025} \mathrm{Ti}_{0.80685} \mathrm{Mn}_{0.002475} \mathrm{Nb}_{0.002475} \mathrm{Zr}_{0.1782} \mathrm{O}_{3}$ (BCTMNZ) ceramics
}

\author{
Radheshyam Rai**, Poonam Kumari* and M. A. Valente ${ }^{\dagger}$ \\ *School of Physics, Shoolini University, Solan, 173212, HP, India \\ †Departamento de Fisica, i3n, Universidade de Aveiro, \\ Campus Universitario de Santiago, 3810-193 Aveiro, Portugal \\ †rshyam1273@gmail.com
}

\begin{abstract}
Received 18 August 2015; Revised 2 October 2015; Accepted 26 October 2015; Published 28 December 2015
In this paper, we investigated the influence of rare earth $(\mathrm{RE}=\mathrm{La}$ and $\mathrm{Gd})$ doped $\mathrm{Ba}_{0.9575} \mathrm{RE}_{0.04} \mathrm{Ca}_{0.0025} \mathrm{Ti}_{0.80685}$ $\mathrm{Mn}_{0.002475} \mathrm{Nb}_{0.002475} \mathrm{Zr}_{0.1782} \mathrm{O}_{3}$ (BCTMNZ) ceramics were fabricated by using a conventional solid-state reaction method. The doping effects of $\mathrm{La}$ and $\mathrm{Gd}$ on the structural and magnetic properties were studied. The structural pattern of the ceramic samples were investigated by X-ray diffraction and the results indicated that both samples shows an orthorhombic structure with pure phase. Strain and crystalline size values for Gd and La doped were $0.31-0.33 \%$ and $0.154-0.181 \mu \mathrm{m}$, respectively. The room temperature hysteresis loops were obtained by using a vibrating sample magnetometer. La doped ceramic showed the higher value of magnetization i.e., $0.369 \mu$ B/f.u. as compared to Gd doped BLTMNZ ceramics.
\end{abstract}

Keywords: Ceramics; X-ray diffraction; lattice strain; magnetic properties.

\section{Introduction}

Barium titanate $\left(\mathrm{BaTiO}_{3}\right)$ is a well-known ferroelectric perovskite material. Due to their high dielectric constant, low dielectric loss, and excellent electrical properties, $\mathrm{BaTiO}_{3}$ based ceramics are universally used for multilayer ceramic capacitors (MLCCs). ${ }^{1,2}$ Among rare earth dopants have a significant effect on the fabrication of MLCCs, and the doping mechanisms of rare earth elements on dielectric properties have been extensively investigated. ${ }^{3-10}$ In general, the ionic radii of the $\mathrm{BaTiO}_{3}$ elements vary between $\mathrm{Ba}^{2+}$ $(0.135 \mathrm{~nm})$ and $\mathrm{Ti}^{4+}(0.068 \mathrm{~nm})$. According to Tsur et al. ${ }^{4}$ larger rare earth ions ( $\mathrm{La}, \mathrm{Nd}, \mathrm{Sm}$, etc.) prefer to occupy A sites as donors, whereas the smaller ions tend to occupy B sites as acceptors, such as $\mathrm{Lu}$ and $\mathrm{Yb}$. However, the substitution sites preferred by the intermediate ions (e.g., Dy, Y, $\mathrm{Ho}$, and Er) are not exclusive to one type, because such ions can occupy not only A sites but B sites as well. In such cases, the preferred substitution site heavily depends on the concentration, sintering temperature, sintering atmosphere, and the $\mathrm{Ba} / \mathrm{Ti}$ molar ratio. ${ }^{7,11-14}$ The dielectric properties of $\mathrm{BaTiO}_{3}$ can be modified by the addition of the dopants such as $\mathrm{La}^{3+}, \mathrm{Mn}^{4+}, \mathrm{Nb}^{5+}$, and $\mathrm{Zr}^{4+}$ to occupy $\mathrm{Ba}^{2+}$ on A sites or $\mathrm{Ti}^{4+}$ on B sites to form the solid solution. ${ }^{15-17}$ Recently many researchers studied the effect of rare-earth doping on $\left(\mathrm{Ba}_{1-x} \mathrm{Ln}_{x}\right) \mathrm{Zr}_{0.2} \mathrm{Ti}_{0.8-x / 4} \mathrm{O}_{3}(\mathrm{Ln}=\mathrm{La}, \mathrm{Sm}, \mathrm{Eu}, \mathrm{Dy}, \mathrm{Y})$ ceramics. Chou et al. reported that the diffuseness of the phase transition and the degree of ferroelectric relaxor behavior are enhanced by the doping. The rare-earth ions with various ionic radii enter the unit cell to substitute for $\mathrm{A}$-site $\mathrm{Ba}^{2+}$ ions and inhibit the grain growth. ${ }^{18}$ Nanakorn et al. ${ }^{19}$ recently address the dielectric and ferroelectric properties of $\mathrm{Ba}$ $\left(\mathrm{Ti}_{1-x} \mathrm{Zr}_{x}\right) \mathrm{O}_{3}$ ceramics by optimizing $\mathrm{Zr}$ content, but the piezoelectric properties are not reported. The effects of $\mathrm{Nb}_{2} \mathrm{O}_{5}$ addition on the dielectric properties and phase formation of $\mathrm{BaTiO}_{3}$ were investigated. Yuan et al. reported that the coreshell structure was formed for $\mathrm{Nb}$-doped $\mathrm{BaTiO}_{3}$ resulted from a low diffusivity of $\mathrm{Nb}^{5+}$ ions into $\mathrm{BaTiO}_{3}$ when grain growth was inhibited and $\mathrm{Nb}^{5+}$ reported as donor ion and reduce the leakage current. ${ }^{20,21}$ Parjansri et al. ${ }^{22}$ synthesized the $\mathrm{Nb}^{5+}$ doped $\mathrm{Ba}_{0.90 \mathrm{Ca} .10} \mathrm{Zr}_{0.10} \mathrm{Ti}_{0.90} \mathrm{O}_{3}$ ceramics by using solid-state reaction method and reported that the average grain size values vary in the range $12.62-1.86 \mu \mathrm{m}$. In their paper they reported that $\mathrm{Nb}$ doping lead to decrease the ferroelectric, piezoelectric, and electromechanical properties. The $\mathrm{Mn}^{4+}$ ion changes the electrical and dielectric properties of barium titanate ceramics and also has a beneficial effect on the reduction of dissipation factor. ${ }^{23,24}$ Kumari et al. fabricated $\mathrm{Ca}$ doped $\left(\mathrm{Ba}_{0.9575} \mathrm{La}_{0.04}\right) \quad\left(\mathrm{Ti}_{0.815} \mathrm{Mn}_{0.0025} \mathrm{Nb}_{0.0025}{ }^{-}\right.$ $\left.\mathrm{Zr}_{0.18}\right)_{0.99} \mathrm{O}_{3}$ (BLTMNZ) ceramic material by solid-state reaction method and reported dielectric properties with low dielectric loss. ${ }^{25}$ Miao et al. studied $\left(\mathrm{Ba}_{1-x} \mathrm{Ca}_{x}\right)\left(\mathrm{Ti}_{1-y} \mathrm{Zr}_{y}\right) \mathrm{O}_{3}$ (BCTZ) dielectric materials for its excellent dielectric and piezoelectric properties. ${ }^{26}$ The high dielectric constant and relative low dielectric loss make BCTZ an appropriate candidate of energy storage dielectric materials for ceramic capacitors. ${ }^{27,28}$ However, the dielectric properties of BCTZ are sensitive to the change of temperature and electric field.

This is an Open Access article published by World Scientific Publishing Company. It is distributed under the terms of the Creative Commons Attribution 4.0 (CC-BY) License. Further distribution of this work is permitted, provided the original work is properly cited. 
Research work has been carried out to improve the dielectric stability of BCTZ by adjusting the ratios of $\mathrm{Zr}$ and $\mathrm{Ca}$ contents, by coupling with simple metal oxides $\mathrm{MO}_{x}(\mathrm{M}$ is aliovalent metal ions or rare earth ions, such as $\mathrm{Ce}, \mathrm{Ga}){ }^{3,4}$ Chen et al. investigated the effects of $\mathrm{Ca}^{2+}$ doped into $\left(\mathrm{Ba}_{1-x} \mathrm{Ca}_{x}\right)$ $\left(\mathrm{Ti}_{1-y} \mathrm{Zr}_{y}\right) \mathrm{O}_{3}$ (BCTZ) ceramics on microstructure and dielectric properties and found that the shift of $\mathrm{Ca}^{2+}$ from Asites to B-sites greatly influences the unit cell volume and the Curie temperature of BCTZ ceramics. ${ }^{29}$ The piezoelectric properties of $\left(\mathrm{Ba}_{0.95} \mathrm{Ca}_{0.05}\right)\left(\mathrm{Ti}_{0.88} \mathrm{Zr}_{0.12}\right) \mathrm{O}_{3}$ ceramics could be further enhanced by optimizing the content of dopants provided that there is a morphotropic phase boundary (MPB) or a polymorphic phase transition (PPT) associated with dopant content. Various research papers are reported on electrical and dielectric properties of $\left(\mathrm{Ba}_{1-x} \mathrm{Ca}_{x}\right)\left(\mathrm{Ti}_{1-y} \mathrm{Zr}_{y}\right) \mathrm{O}_{3}$ ceramics, but no literature reported on the magnetic properties of rare earth (La and $\mathrm{Gd}$ ) doped at the A-site and $\mathrm{Mn}$ and $\mathrm{Nb}$ ions at B-site of BCTZ ceramics. La and Gd ions increases the solubility of the system and decreases the grain growth and phase transition temperature. Influence of $\mathrm{Nb}$ and $\mathrm{Mn}$ doping increases the density and magnetic property of ceramics. The substitution of $\mathrm{Gd}$ and $\mathrm{La}$ at $\mathrm{A}$-site also affected the conduction and magnetic properties of the system due to its magnetic moment. Therefore, in this study the structural and magnetic properties of doping $\mathrm{La}$ and $\mathrm{Gd}$ ions at the A-site and $\mathrm{Mn}$ and $\mathrm{Nb}$ ions at B-site of BCTZ lead-free ceramics synthesized by solid-state reaction method.

The phase stability and transformation of perovskite ceramics can be explained using the tolerance factor $(t)$ described by Ullah et al. ${ }^{30}$ The degree of distortion in the actual perovskite structure, owing to mismatch in the ionic size, valence state, and electronegativity difference between the solute and solvent atoms, is generally estimated in terms of the tolerance factor $t^{31}$ defined by using Eq. 1 given below.

$$
t=\frac{R_{A}+R_{O}}{\sqrt{2}\left(R_{B}+R_{O}\right)},
$$

where $R_{O}, R_{A}$, and $R_{B}$ are the ionic radius of oxygen atom, and average ionic radius of $A$ and $B$ atoms, respectively. For complex perovskite system, $R_{A}$ and $R_{B}$ are the ionic radii of composed ions normalized by the atomic ratio and ionic radii refer to those reported by Shannon. ${ }^{32}$ In general, the perovskite structure is stable in the region $0.71<t<1.090$. The $t$-value of an orthorhombic is close to 1 . The $t$-value also provides an indication about how far the atoms can move from the ideal packing positions and be still "tolerated" in the perovskite structure. The purpose of this study is to investigate with a special emphasis on the influence of $\mathrm{La}$ and $\mathrm{Gd}$ on the structural and magnetic properties of BCTMNZ ceramics.

\section{Experimental Procedure}

The barium zirconate titanate-based ceramics were prepared by conventionally mixed-oxide method. Suitable stoichiometric amounts of high purity oxides of $\mathrm{TiO}_{2}$ (Aldrich
99.9\%), $\mathrm{BaCO}_{3}$ (Aldrich 99.9\%), $\mathrm{La}_{2} \mathrm{O}_{3}$ (Aldrich 99.9\%), $\mathrm{Gd}_{2} \mathrm{O}_{3}$ (Aldrich 99.9\%), $\mathrm{CaCO}_{3}$ (Aldrich 99.9\%), $\mathrm{ZrO}_{2}$ (Aldrich 99.9\%), $\quad \mathrm{Nb}_{2} \mathrm{O}_{5}$ (Aldrich 99.9\%), and $\mathrm{Mn}_{2} \mathrm{O}_{3}$ (Aldrich 99.9\%), raw materials were used as starting materials according to the formula $\left(\mathrm{Ba}_{0.9575} \mathrm{RE}_{0.04} \mathrm{Ca}_{0.0025}\right)$ $\left(\mathrm{Ti}_{0.815} \mathrm{Mn}_{0.0025} \mathrm{Nb}_{0.0025} \mathrm{Zr}_{0.18}\right)_{0.99} \mathrm{O}_{3}$ (where $\mathrm{RE}=\mathrm{La}$ and $\mathrm{Gd}$ ). Weighted source powders were mixed by ball milling for $\sim 24 \mathrm{~h}$ using $\mathrm{ZrO}_{2}$ balls in acetone media. The mixed powders were dried and calcined for $6 \mathrm{~h}$ at $\sim 1100^{\circ} \mathrm{C}$. The calcined powder was grounded in a mortar pestle to obtain fine powder. The grinding process was repeated for $\sim 8 \mathrm{~h}$ in the presence of PVA as binding liquid. After grinding the powders were uniaxially pressed into pellets of approximately $10 \mathrm{~mm}$ diameter and sintered at a temperature of $1200^{\circ} \mathrm{C}$ for $2 \mathrm{~h}$ in a high temperature muffle furnace. The X-ray diffraction pattern of the compounds were recorded at room temperature using X-ray powder diffractometer with $\mathrm{CuK}_{\alpha}$ $(\lambda=1.5418 \AA$ ) radiation (Rigaku Minifiex, Japan) in a wide range of Bragg angles $2 \theta\left(20^{\circ} \leq 2 \theta \leq 60^{\circ}\right)$ at a scanning rate of $2^{\circ} \mathrm{min}^{-1}$. The magnetic properties of the La and Gd doped BCTMNZ sample can be determined at room temperature using vibrating sample magnetometer (VSM).

\section{Results and Discussion}

\subsection{Structural properties}

Figures 1(a) and 1(b) show the room temperature XRD patterns of the RE doped $\left(\mathrm{Ba}_{0.9575} \mathrm{RE}_{0.04} \mathrm{Ca}_{0.0025}\right)$ $\left(\mathrm{Ti}_{0.815} \mathrm{Mn}_{0.0025} \mathrm{Nb}_{0.0025} \mathrm{Zr}_{0.18}\right) \mathrm{O}_{3}$ perovskite type ceramics. All the reflection peaks were indexed using observed interplanar spacing $d$ and lattice parameters of $\mathrm{Re}$ doped BCTMNZ were determined using a least squares refinement method by using a computer program package Powder. ${ }^{33}$ Finally, orthorhombic unit cell was selected on the basis of good agreement between observed $\left(d_{\text {obs }}\right)$ and calculated $\left(d_{\text {cal }}\right)$ interplanar spacing $d$ (i.e. $\Sigma \Delta d=\Sigma\left(d_{\text {obs }}-d_{\text {cal }}\right)=$ minimum) of the peaks. The refined lattice parameters of $\mathrm{La}$ and Gd doped BCTMNZ samples are given in Table 1.

Figure 1(b) shows that the diffraction peaks are shifted towards the higher angle side. In fact, decreasing the lattice constants and the unit cell volume cause the shift in peaks position to higher angles, ${ }^{34,35}$ the shifting of the peaks to higher $2 \theta$ angle due the smaller ionic radii of the dopants atoms i.e., $R_{\mathrm{Gd}^{3+}}<R_{\mathrm{La}^{3+}}$. Therefore, the average ionic radius of the A-site $<R_{A}>$ is systematically decreased for Gd doped $\left(R_{\mathrm{Gd}^{3+}}=0.938 \mathrm{~A}\right) \mathrm{BCTMNZ}$ samples. The calculated value of tolerance factor for $\mathrm{La}$ and Gd doped BCTMNZ samples is 0.92 and 0.90 , respectively, which indicate the orthorhombic structure of the samples. The presence of sharp single peaks of varying intensity in the XRD pattern indicates formation of pure single phase of perovskite structure. The reflection lines of XRD pattern of $\mathrm{La}$ and Gd doped BCTMNZ ceramics were used for obtaining the crystalline size. XRD peaks from the (110), (011), (200), and (120) planes of La doped 


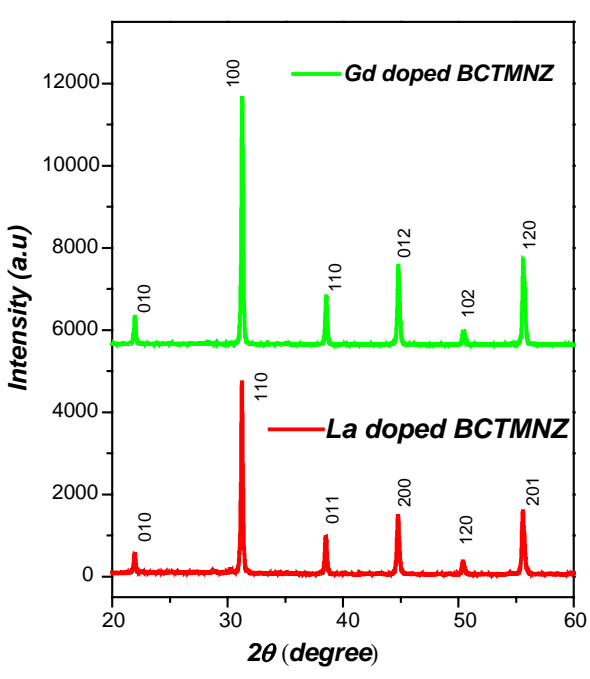

(a)

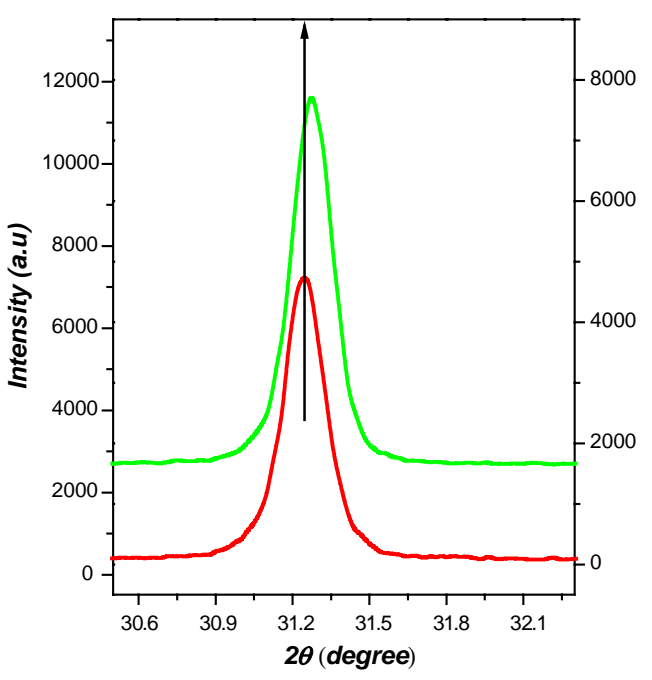

(b)

Fig. 1. (a) X-Ray diffraction patterns of La and Gd doped BCTMNZ ceramics. (b) XRD peak splitting at $2 \theta=31.21$.

Table 1. Comparison of some observed and calculated $d$-values (in $\AA$ ) along with ( $h k l$ ) of some reflections of (La and Gd) RE- doped $\mathrm{Ba}_{0.9575} \mathrm{Ca}_{0.0025} \mathrm{Ti}_{0.80685} \mathrm{Mn}_{0.002475} \mathrm{Nb}_{0.002475} \mathrm{Zr}_{0.1782} \mathrm{O}_{3}(\mathrm{BCTMNZ})$ ceramics at room temperature.

\begin{tabular}{|c|c|c|c|c|c|c|c|c|c|}
\hline \multicolumn{5}{|c|}{ La doped BCTMNZ } & \multicolumn{5}{|c|}{ Gd doped BCTMNZ } \\
\hline \multirow[b]{2}{*}{ Lattice parameters $(\AA)$} & \multirow[b]{2}{*}{ Crystal system } & \multicolumn{2}{|c|}{$d$-spacing $(\AA ̊)$} & \multirow[b]{2}{*}{$h k l$} & \multirow[b]{2}{*}{ Lattice parameters $(\AA)$} & \multirow[b]{2}{*}{ Crystal system } & \multicolumn{2}{|c|}{$d$-spacing $(\AA)$} & \multirow[b]{2}{*}{$h k l$} \\
\hline & & $d_{\mathrm{obs}}$ & $d_{\text {cal }}$ & & & & $d_{\text {obs }}$ & $d_{\mathrm{cal}}$ & \\
\hline \multirow[t]{2}{*}{$a=4.0444$} & \multirow[t]{6}{*}{ Orthorhombic } & 4.0368 & 4.0368 & 010 & $a=2.8590$ & Orthorhombic & 4.0144 & 4.0140 & 010 \\
\hline & & 2.8571 & 2.8571 & 110 & & & 2.8389 & 2.8390 & 100 \\
\hline \multirow[t]{2}{*}{$b=4.0368$} & & 2.3328 & 2.3328 & 011 & $b=4.0244$ & & 2.3163 & 2.3163 & 110 \\
\hline & & 2.0221 & 2.0222 & 200 & & & 2.0230 & 2.0230 & 012 \\
\hline \multirow[t]{2}{*}{$c=2.8584$} & & 1.8064 & 1.8064 & 120 & $c=4.0672$ & & 1.8090 & 1.8091 & 102 \\
\hline & & 1.6510 & 1.6508 & 201 & & & 1.6510 & 1.6510 & 120 \\
\hline
\end{tabular}

BCTMNZ and (100), (110), (012), and (102) planes of Gd doped XRD pattern are fitted with Gaussian function as shown in Figs. 2(a) and 2(b). The standard error of the Gaussian fitting is 0.00142 . The coefficient of determination of fitted peaks to Gauss function are closer to unity compared to other functions. The value of the goodness of fit $\left(R^{2}\right)$ of a regression very close to unity indicates that a regression line fits the data well. The error of fitting and the value of $R^{2}$ for different fitted peaks are shown in Figs. 2(a) and 2(b) by using Gaussian function. The crystallite sizes and lattice or micro strain were calculated by the slope of Williamson-Hall (W-H) plots as shown in Figs. 3(a) and 3(b). According to $\mathrm{W}-\mathrm{H}$ method $^{36}$ the width of individual reflections can be expressed as follows,

$$
\text { FWHM }_{\text {tot. }} \cos \theta=\frac{K \lambda}{D}+C \varepsilon_{0} \sin \theta,
$$

$D=$ grain diameter,

$k=0.9$ to 1.0 depending upon grain shape, $\lambda=1.54056$,

$C \varepsilon_{0}=$ Strain in material,

$$
y=m x+C .
$$

Comparing (2) and (3), $m=C \varepsilon_{0}=$ slope $=$ strain of the sample. The parameters calculated by $\mathrm{W}-\mathrm{H}$ method for $\mathrm{La}$ and Gd doped BCTMNZ samples are given in Table 2.

Figures 3(a) and 3(b) show the variations of FWHM tot. $_{\text {. }}$ $\cos \theta$ with $\sin \theta$ of the various reflecting planes for $\mathrm{La}$ and $\mathrm{Gd}$ doped BCTMNZ ceramics. Moreover, the fitted straight line has been plotted in this figure. According to Eq. 2, it can be concluded that the strain of La and Gd doped BCTMNZ ceramics are 0.00309 and 0.00338 , respectively. Strain in the lattice is a measure of the distribution of lattice constants arising from crystal imperfections, such as lattice dislocations, grain boundary triple junction, contact or sinter stresses, stacking faults and coherency stresses. ${ }^{37}$ Extrapolation of the graph to $\sin \theta=0$, gives $\frac{K \lambda}{D}$ as the intercept on the 

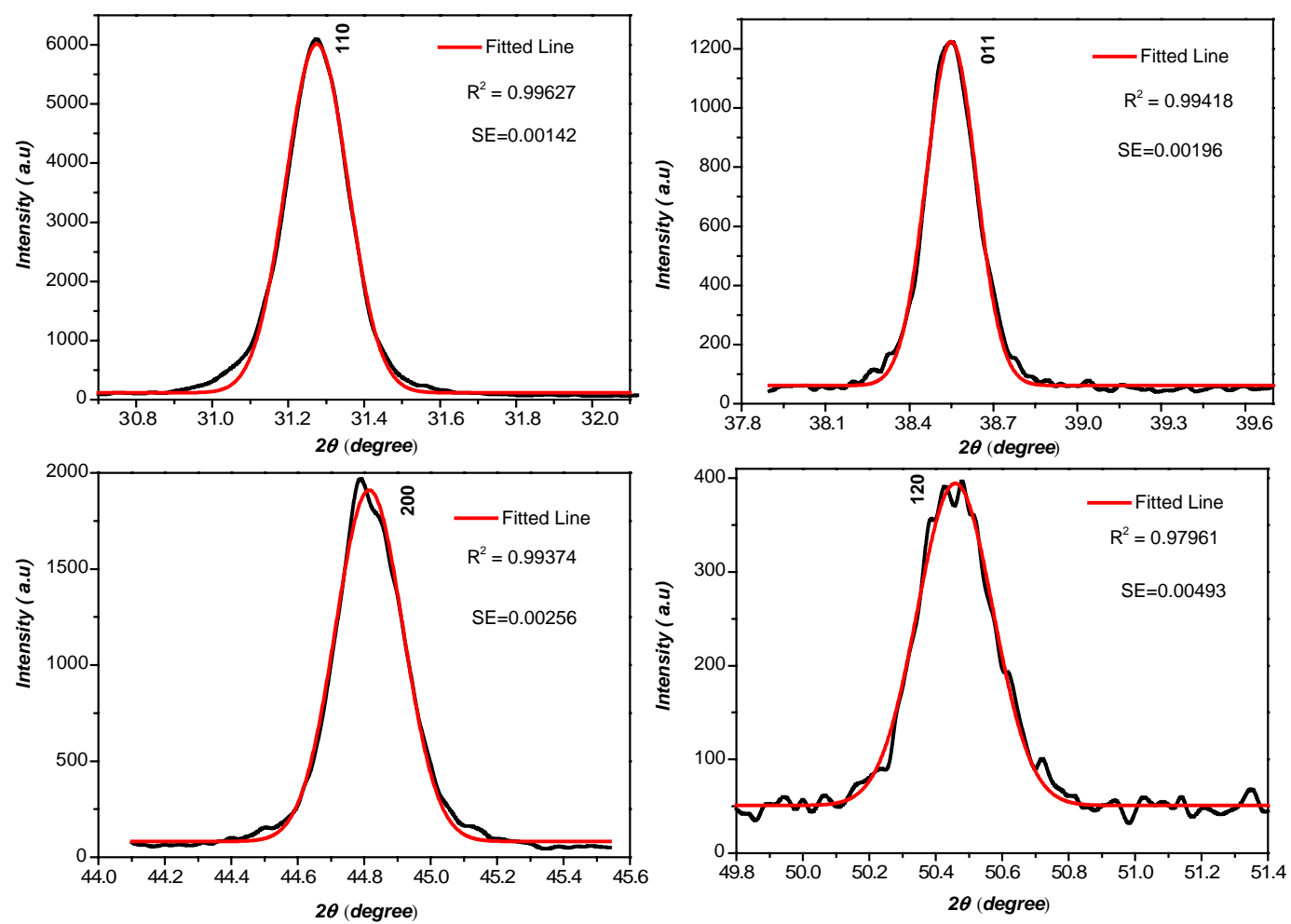

(a)
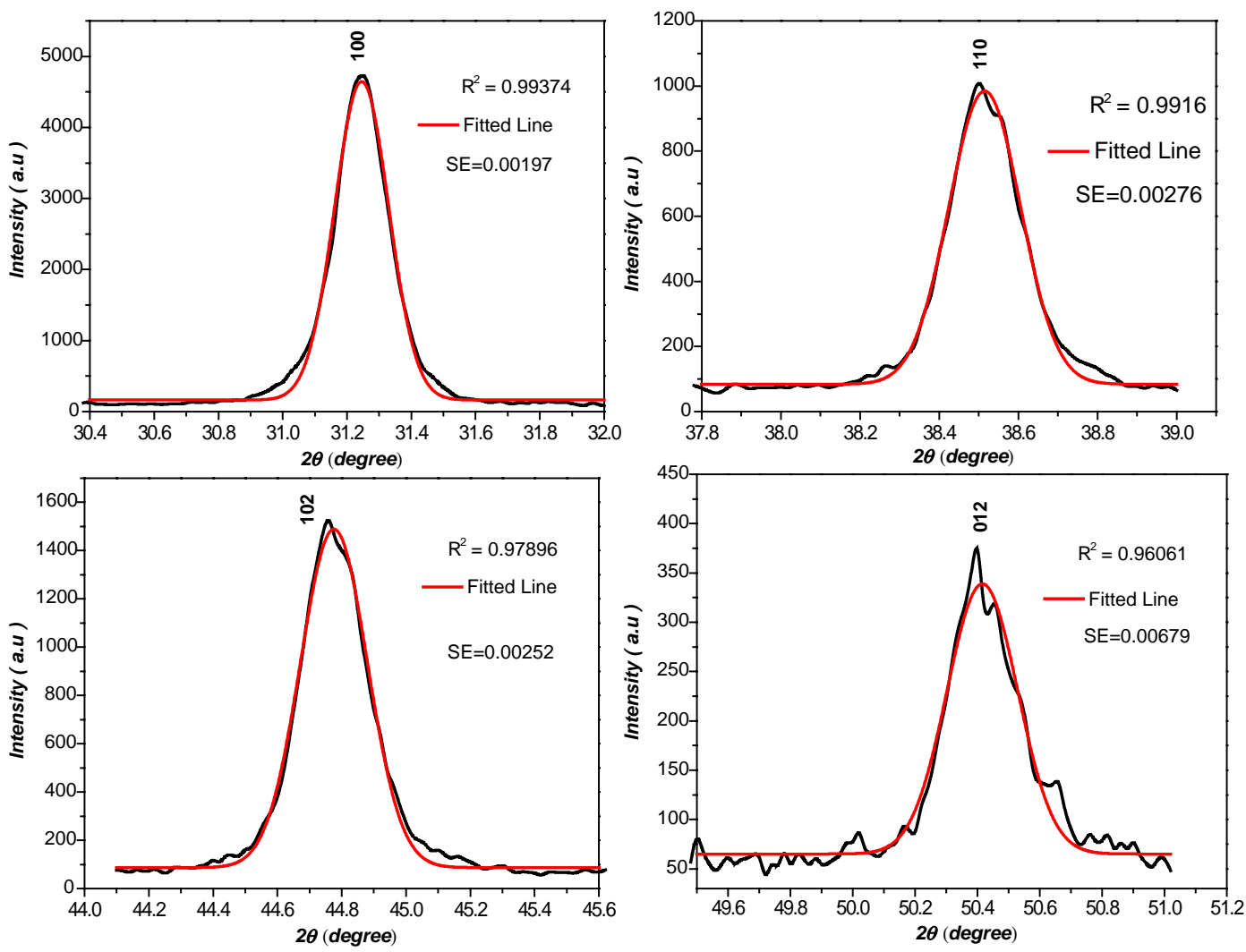

(b)

Fig. 2. XRD peaks from the (110), (011), (200), and (120) planes of La doped BCTMNZ. (b) Peaks from the (100), (110), (012), and (102) planes of Gd doped BCTMNZ ceramic fitted to the Gaussian function. 


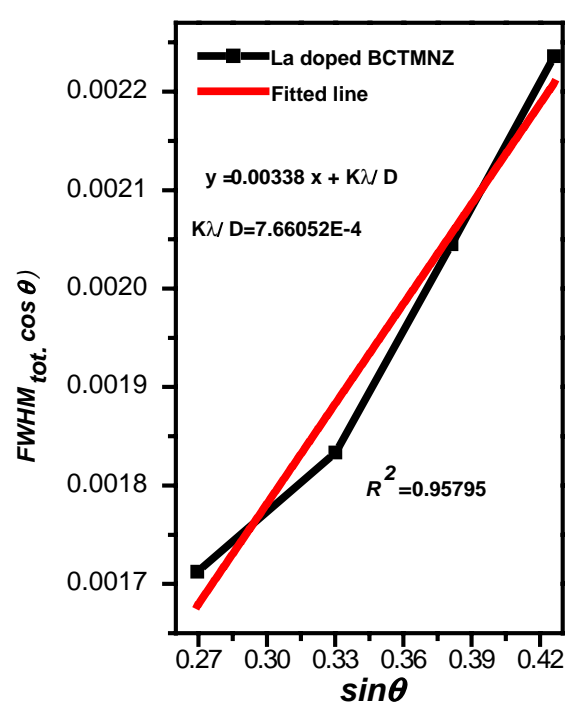

(a)

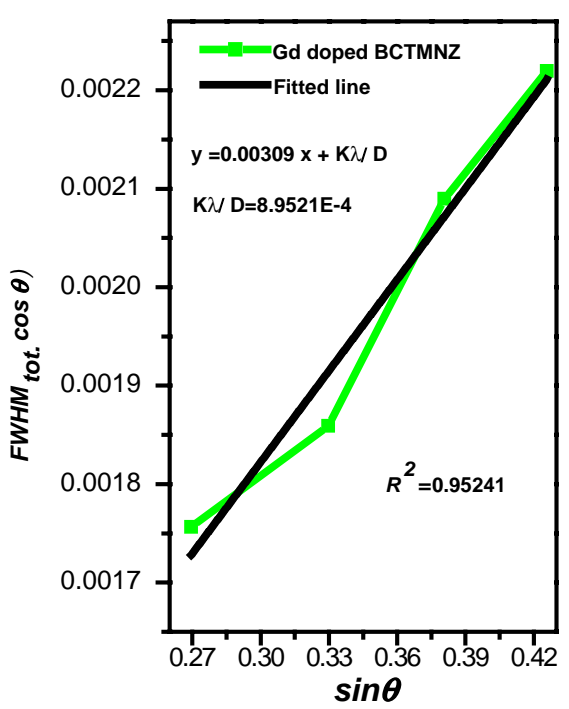

(b)

Fig. 3. W-H plots of La and Gd doped BCTMNZ ceramics.

Table 2. Various parameters calculated from XRD patterns by using W-H Plot.

\begin{tabular}{|c|c|c|c|c|c|c|c|}
\hline \multirow[b]{2}{*}{ Sample } & \multirow[b]{2}{*}{$2 \theta$} & \multirow[b]{2}{*}{$<h k l>$} & \multicolumn{5}{|c|}{ W-H method } \\
\hline & & & $\sin \theta$ & $\cos \theta$ & $\mathrm{FWHM}_{\text {tot. }}(\mathrm{rad})$ & Crystallite size $(\mathrm{nm})$ & Strain $\left(\mathrm{C} \varepsilon_{0}\right)(\%)$ \\
\hline \multirow[t]{4}{*}{ La doped BCTMNZ } & 31.28 & 110 & 0.00142 & & 0.00171 & 181 & 0.33 \\
\hline & 38.56 & 011 & 0.00196 & & 0.00183 & & \\
\hline & 44.8 & 200 & 0.00256 & & 0.00204 & & \\
\hline & 50.46 & 120 & 0.00225 & & 0.00224 & & \\
\hline \multirow[t]{4}{*}{ Gd doped BCTMNZ } & 31.26 & 100 & 0.00197 & & 0.00176 & 154 & 0.31 \\
\hline & 38.5 & 110 & 0.00276 & & 0.00186 & & \\
\hline & 44.76 & 102 & 0.00252 & & 0.00209 & & \\
\hline & 50.42 & 012 & 0.00311 & & 0.00222 & & \\
\hline
\end{tabular}

FWHM $_{\text {tot. }} \cos \theta$ axis, from which the average crystallite size was estimated to be 0.181 and $0.154 \mu \mathrm{m}$ for La and Gd doped BCTMNZ ceramics, respectively. Peak broadening (FWHM) has been used to determine the crystallite sizes using the Sherrer's formula. It is observed that crystallite size also increased for the $\mathrm{La}^{3+}$ doping. The lattice parameter and crystallite size induces a lattice strain in the crystal structure. This may be explained on the basis of defects present in the sample, which allows the absorption of lattice strain caused by the dopant amounts. ${ }^{38,39}$

\subsection{Magnetic properties}

The magnetic moment as a function of temperature between 5 and $300 \mathrm{~K}$ under zero-field cooled (ZFC) and field cooled (FC) conditions with an applied magnetic field of $0.1 \mathrm{~T}$ is given in Figures 4(a) and 4(b). The high magnetization value at the lower temperature suggests the presence of uncompensated antiferromagnetic spins. Initially magnetization decreases with an increase in temperature, and then constant.
It is clear that the ZFC and FC lines have no magnetic transition in this temperature range $(5-300 \mathrm{~K})$. Magnetic measurements in the temperature range 5-300 K indicated that the magnetization of La and Gd doped BCTMNZ is due to the spontaneous magnetic, and the other susceptibility term, attributable to the paramagnetic property of La and $\mathrm{Gd}$ sublattice. ${ }^{40}$ The variation of $M-T$ curves with $\mathrm{La}$ and $\mathrm{Gd}$ doped BCTMNZ ceramics may be attributed to different factors like (i) variation in the oxygen stoichiometric and doping at A and B sites, (ii) reduction in particle size, and (iii) change in the magnetic anisotropy. ${ }^{41}$

Figure 5(a) and (5c) show the magnetic hysteresis loops measured at $5 \mathrm{~K}, 150 \mathrm{~K}$ and $300 \mathrm{~K}$ for $\mathrm{La}$ and $\mathrm{Gd}$ doped BCTMNZ ceramics. The hysteresis loops indicate the effect of temperature on the magnetization with magnetic field of the samples. The highest magnetization and $\mathrm{M}-\mathrm{H}$ loop area were found for $5 \mathrm{~K}$ for La and Gd doped BCTMNZ ceramics due to antiferromagnetic behavior of lanthanides below room temperature. The cycloid spin structure could be suppressed and the net magnetization will be enhanced by the 


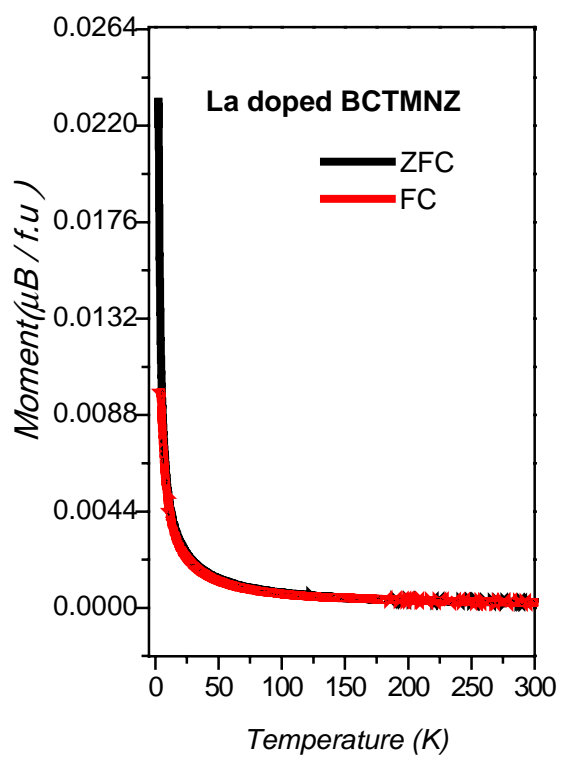

(a)

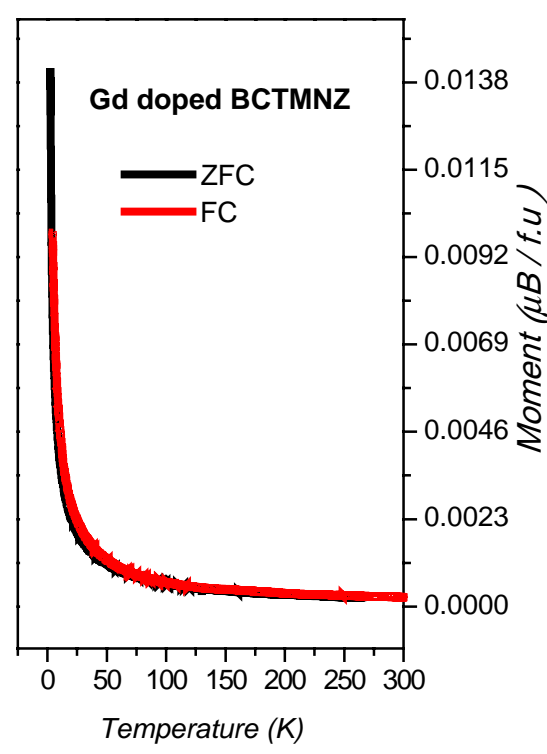

(b)

Fig. 4. Variation of magnetization FC and ZFC of La and Gd doped BCTMNZ ceramics with temperature (K).

uncompensated spins, as well as the spin due to surface strain. ${ }^{42-46}$ In Figure 5(b) and 5(c), $M-H$ loops of sample at 150 and $300 \mathrm{~K}$ exhibit linear loop indicating bulk polycrystalline behavior. They exhibit no magnetic irreversibility in agreement with ZFC-FC magnetization, and an almost linear dependence of magnetization on the applied magnetic field.
Figure 5(d) shows the variation of maximum magnetization with temperature for both compositions. Maximum magnetization for samples decreases with increasing temperature. Magnetization of La doped is $0.369 \mu \mathrm{B} / \mathrm{f}$.u which is higher due to the greater crystalline size and lattice strain than $\mathrm{Gd}$ doped BCTMNZ ceramics. The Gd, La or Mn ions give rise

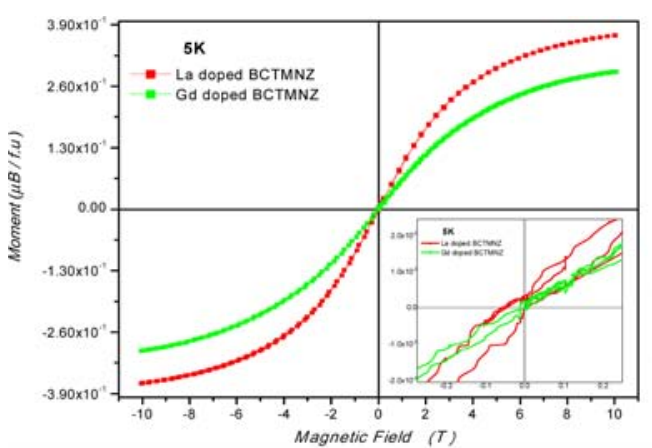

(a)

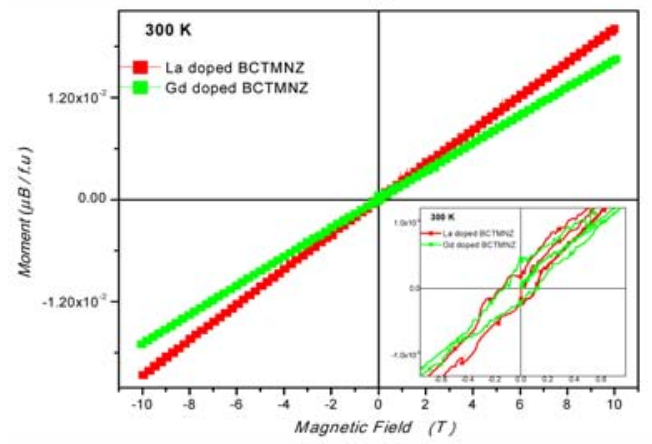

(c)

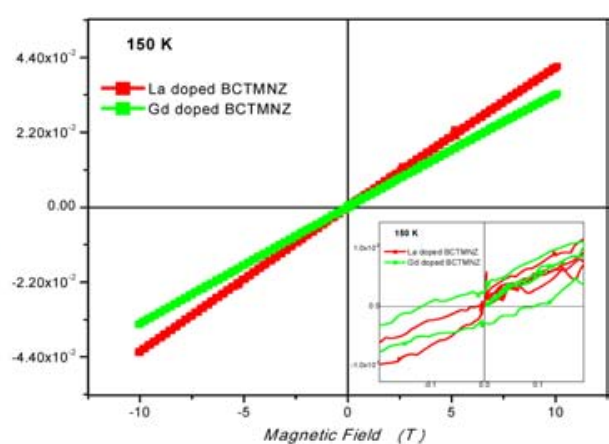

(b)

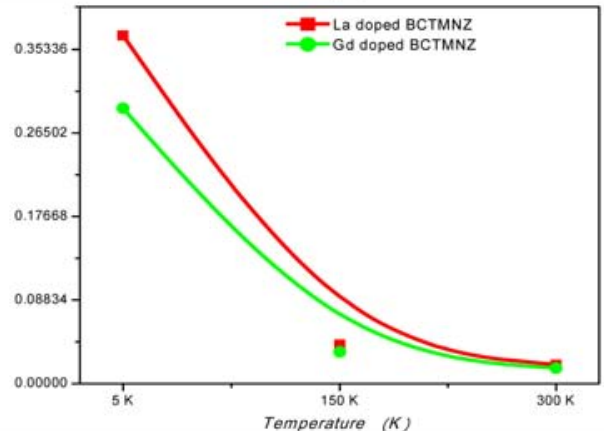

(d)

Fig. 5. M-H loops of La and Gd doped BCTMNZ ceramics at (a) $5 \mathrm{~K}$, (b) $150 \mathrm{~K}$, (c) $300 \mathrm{~K}$, and (d) variation of saturated magnetization (M ${ }_{s}$ ) with temperature $(\mathrm{K})$ of $\mathrm{La}$ and $\mathrm{Gd}$ doped BCTMNZ ceramics. 


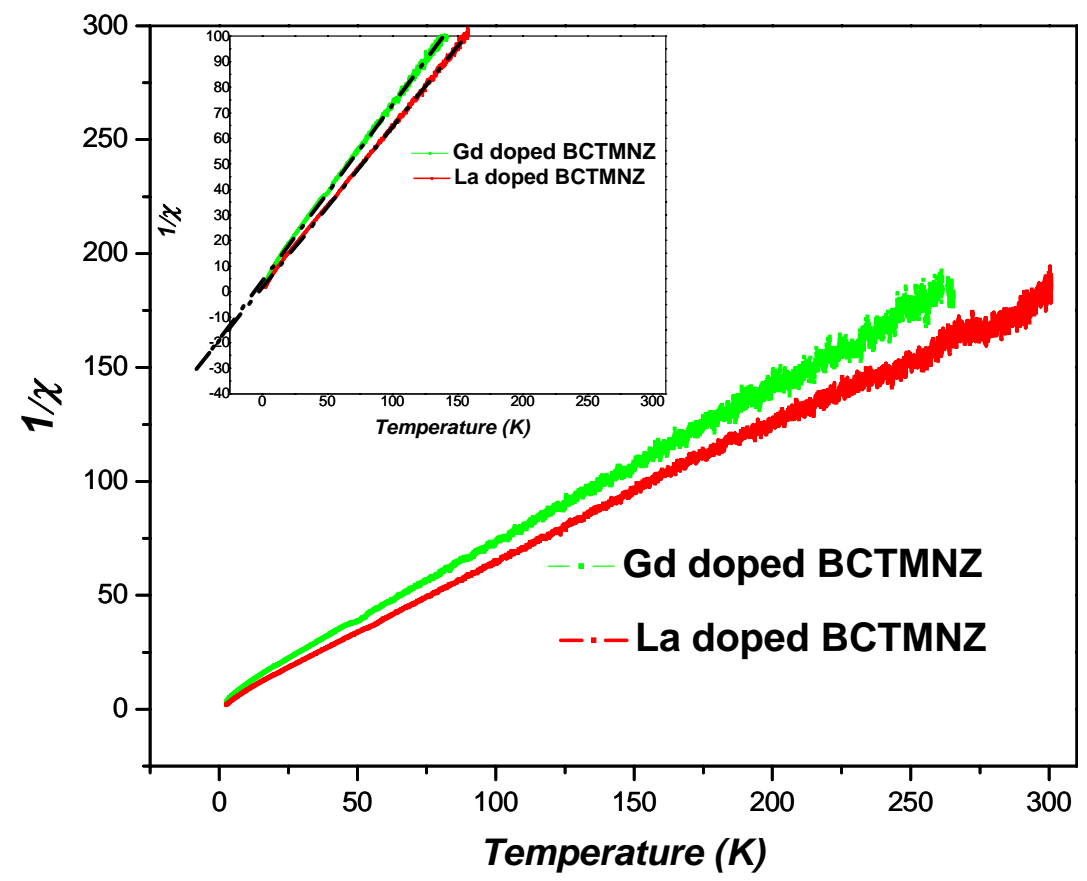

Fig. 6. Variation of inverse of magnetic susceptibility $(\chi)$ with temperature $(\mathrm{K})$ of La and Gd doped BCTMNZ ceramics.

to similar hole doping effects, but the $\mathrm{Mn}$ ion also act as strong localization centers for the holes and severely reduce the strength of the ferromagnetic exchange interaction. Magnetic property of doped manganites is associated basically with the change in the ratio of $\mathrm{Mn}^{3+} / \mathrm{Mn}^{4+}$ ions due to divalent ion substitution by $\mathrm{Ca}$ and $\mathrm{Ba}$ ions and trivalent ion substitution by $\mathrm{Gd}$ or La ions. ${ }^{43,47,48}$

Figure 6 shows variation of inverse magnetic susceptibility with temperature at $1 \mathrm{~T}$ magnetic field using relation $\chi=\frac{C}{\left(T-\theta_{C}\right)}$ where $\chi$ magnetic susceptibility, $\theta_{C}$ is Curie temperature coefficient, and $C$ is the constant. The curves consist of linear Curie-Weiss type regions at different temperatures. The values of the Curie constant and asymptotic Curie temperature, extracted from the linear regions of the $1 / \chi$ versus $T$ curves, indicate that the values of the Curie temperature is negative for both samples, which indicate the predominance of antiferromagnetic interactions. ${ }^{49}$

\section{Conclusion}

We have developed a simple method to prepare single-phase, $\mathrm{La}$ and $\mathrm{Gd}$ doped BCTMNZ ceramics. The ceramics prepared under the optimized conditions show an orthorhombic crystal structure. The lattice strain and crystalline size of $\mathrm{La}$ doped and $\mathrm{Gd}$ doped $0.33 \%$ and $0.31 \%$ and $0.181-0.154 \mu \mathrm{m}$, respectively. A minor loop traced and negative values of the Curie temperature for both samples indicates an antiferromagnetic nature with weak ferromagnetism. The higher value of magnetization found for $\mathrm{La}$ doped BCTMNZ ceramics is $0.369 \mu \mathrm{B} / \mathrm{f}$.u at $5 \mathrm{~K}$ due to the greater lattice strain and crystalline size. $M-H$ loops of sample at 150 and $300 \mathrm{~K}$ exhibits linear loop indicating bulk polycrystalline behavior.

\section{Acknowledgments}

Authors are grateful to the Defense Research and Development Organization (DRDO), Govt. of India, for financial support under the research project ERIP/ER/1303129/M/01/1564.

\section{References}

${ }^{1}$ Z. B. Shen, X. H. Wang, H. L. Gong and L. T. Li, Structural and dielectric properties of rare earth (Y, Ho) doped $\mathrm{Ba} 0.95 \mathrm{Ca} 0.05-$ Ti0.85Zr0.15O3 ceramics, Key Eng. Mater. 602-603, 728 (2014).

${ }^{2}$ Y. Sakabe, Multilayer ceramic capacitors, Curr. Opin. Solid State Mater. Sci. 2, 584 (1997).

${ }^{3}$ Z. Shen, X. Wang, H. Gong, L. Wu and L. Li, Effect of $\mathrm{MnO} 2$ on the electrical and dielectric properties of Y-doped $\mathrm{Ba} 0.95 \mathrm{Ca} 0.05 \mathrm{Ti} 0.85 \mathrm{Zr} 0.15 \mathrm{O} 3$ ceramics in reducing atmosphere, Ceram. Int. 40, 13833 (2014).

${ }^{4}$ Y. Tsur, A. Hitomi, I. Scrymgeour and C. A. Randall, Site occupancy of rare-earth cations in BaTiO 3, Jpn. J. Appl. Phys. 40, 255 (2001).

${ }^{5} \mathrm{P}$. Yongping, Y. Wenhu and C. Shoutian, Influence of rare earths on electric properties and microstructure of barium titanate ceramics, J. Rare Earths 25, 154 (2007).

${ }^{6} \mathrm{G}$. Jonker and E. Havinga, The influence of foreign ions on the crystal lattice of barium titanate, Mater. Res. Bull. 17, 345 (1982).

${ }^{7}$ H. Kishi, N. Kohzu, J. Sugino, H. Ohsato, Y. Iguchi and T. Okuda, The effect of rare-earth (La, Sm, Dy, Ho and $\mathrm{Er}$ ) and $\mathrm{Mg}$ on the microstructure in BaTiO 3, J. Eur. Ceram. Soc. 19, 1043 (1999). 
${ }^{8}$ H. Kishi, N. Kohzu, Y. Mizuno, Y. Iguchi, J. Sugino, H. Ohsato and T. Okuda, Effect of occupational sites of rare-earth elements on the microstructure in BaTiO3, Jpn. J. Appl. Phys. 38, 5452 (1999).

${ }^{9}$ H. Kishi, N. Kohzu, N. Ozaki, H. Ohsato and T. Okuda, Effect of occupational sites of rare-earth elements on the Curie point in BaTiO 3, Proc. 13th IEEE Int. Symp. Applications of Ferroelectrics, 2002. ISAF 2002 (IEEE, 2002), pp. 271-276.

${ }^{10} \mathrm{~V}$. J. Tennery and R. L. Cook, Investigation of rare-earth doped barium titanate, J. Am. Ceram. Soc. 44, 187 (1961).

${ }^{11}$ K.-J. Park, C.-H. Kim, Y.-J. Yoon, S.-M. Song, Y.-T. Kim and K.-H. Hur, Doping behaviors of dysprosium, yttrium and holmium in BaTiO 3 ceramics, J. Eur. Ceram. Soc. 29, 1735 (2009).

${ }^{12}$ G. Lewis and C. Catlow, Defect studies of doped and undoped barium titanate using computer simulation techniques, J. Phys. Chem. Solids 47, 89 (1986).

${ }^{13}$ L. A. Xue, Y. Chen and R. J. Brook, The influence of ionic radii on the incorporation of trivalent dopants into BaTiO 3, Mater. Sci. Eng. B 1193 (1988).

${ }^{14}$ T. Murakami, T. Miyashita, M. Nakahara and E. Sekine, Effect of rare-earth ions on electrical conductivity of BaTiO3 ceramics, $J$. Am. Ceram. Soc. 56, 294 (1973).

${ }^{15}$ V. V. Mitic, Z. S. Nikolic, V. B. Pavlovic, V. Paunovic, M. Miljkovic, B. Jordovic and L. Zivkovic, Influence of rare-earth dopants on barium titanate ceramics microstructure and corresponding electrical properties, J. Am. Ceram. Soc. 93, 132 (2010).

${ }^{16}$ P. Om, D. Kumar, R. K. Dwivedi, K. K. Srivastava, P. Singh and S. Singh, Effect of simultaneous substitution of $\mathrm{La}$ and $\mathrm{Mn}$ on dielectric behavior of barium titanate ceramic, J. Mater. Sci. 42, 5490 (2007).

${ }^{17}$ D.-Y. Lu, M. Toda and M. Sugano, High-permittivity double rareearth-doped barium titanate ceramics with diffuse phase transition, J. Am. Ceram. Soc. 89, 3112 (2006).

${ }^{18}$ X. Chou, J. Zhai, H. Jiang and X. Yao, Dielectric properties and relaxor behavior of rare-earth ( $\mathrm{La}, \mathrm{Sm}, \mathrm{Eu}, \mathrm{Dy}, \mathrm{Y})$ substituted barium zirconium titanate ceramics, J. Appl. Phys. 102, 084106 (2007).

${ }^{19}$ N. Nanakorn, P. Jalupoom, N. Vaneesorn and A. Thanaboonsombut, Dielectric and ferroelectric properties of $\mathrm{Ba}(\mathrm{ZrxTi} 1-\mathrm{x}) \mathrm{O} 3$ ceramics, Ceram. Int. 34, 779 (2008)

${ }^{20}$ Y. Yuan, S. R. Zhang, X. H. Zhou and B. Tang, Effects of Nb2O5 doping on the microstructure and the dielectric temperature characteristics of barium titanate ceramics, J. Mater. Sci. 44, 3751 (2009).

${ }^{21} \mathrm{~J}$. Jeong and Y. Han, Electrical properties of acceptor doped BaTiO3, J. Electroceram. 13, 549 (2004).

${ }^{22} \mathrm{P}$. Parjansri, U. Intatha and S. Eitssayeam, Dielectric, ferroelectric and piezoelectric properties of $\mathrm{Nb} 5+$ doped BCZT ceramics, Mater. Res. Bull. 65, 61 (2015).

${ }^{23}$ S. H. Cha and Y. H. Han, Effects of Mn doping on dielectric properties of Mg-doped $\mathrm{BaTiO}_{3}$, J. Appl. Phys. 100, 104102 (2006).

${ }^{24}$ C. Chen, G. Wang, L. Wang, C. Lu and Z. Xu, Electrical and magnetic properties of $\mathrm{BiFe} 0.97-\mathrm{xMn0.03ZnxO3}$ thin films with different $\mathrm{Zn}$ content synthesised by chemical solution deposition (CSD), J. Ceram. Process. Res. 12, 664 (2011).

${ }^{25}$ P. Kumari, R. Rai, A. L. Kholkin and A. Tiwari, Study of Ca doping on A-site on the structural and physical properties of BLTMNZ ceramics, Adv. Mater. Lett. 5, 255 (2014).
${ }^{26}$ J. Miao, Z. Zhang, Z. Liu and Y. Li, Investigation on the dielectric properties of $\mathrm{Mg}$-doped (Ba0.95Ca0.05)(Ti0.85Zr0.15)O3 ceramics, Ceram. Int 41, S487-S491 (2015).

${ }^{27}$ S.-W. Zhang, H. Zhang, B.-P. Zhang and S. Yang, Phase-transition behavior and piezoelectric properties of lead-free $(\mathrm{Ba} 0.95 \mathrm{Ca} 0.05)$ (Ti1-xZrx)O3 ceramics, J. Alloys Compd. 506, 131 (2010).

${ }^{28}$ J. Ma, X. Liu and W. Li, High piezoelectric coefficient and temperature stability of $\mathrm{Ga} 2 \mathrm{O} 3$-doped ( $\mathrm{Ba} 0.99 \mathrm{Ca} 0.01)(\mathrm{Zr} 0.02 \mathrm{Ti} 0.98)$ O3 lead-free ceramics by low-temperature sintering, J. Alloys Compd. 581, 642 (2013).

${ }^{29}$ L. Chen, L. Li, X. Wang, Z. Tianand and Z. Gui, The study of Cadoped BCTZ ceramics sintered in reducing atmosphere, J. Electroceram. 21, 569 (2008).

${ }^{30}$ A. Ullah, C. W. Ahn, A. Hussain, S. Y. Lee and I. W. Kim, Phase transition, electrical properties, and temperature-insensitive large strain in BiAlO3-modified Bi0.5(Na0.75K0.25)0.5TiO3 lead-free piezoelectric ceramics, J. Am. Ceram. Soc. 94, 3915 (2011).

${ }^{31}$ R. Choudhary, K. Perez, P. Bhattacharya and R. Katiyar, Structural and dielectric properties of mechanochemically synthesized BiFeO3-Ba(Zr0.6Ti0.4) O3 solid solutions, Mater. Chem. Phys. 105, 286 (2007).

${ }^{32}$ R. T. Shannon, Revised effective ionic radii and systematic studies of interatomic distances in halides and chalcogenides, Acta Crystallogr. A 32, 751 (1976).

${ }^{33} \mathrm{E}$. Wu, POWD, an interactive program for powder diffraction data interpretation and indexing, J. Appl. Crystallogr. 22, 506 (1989).

${ }^{34}$ S. Huang, X. Cui, D. Wang, Z. Han and Y. Du, Magnetic entropy change and magnetotransport in $\mathrm{Gd}$ doped $\mathrm{La}-\mathrm{Sr}-\mathrm{Mn}-\mathrm{O}$ perovskite, J. Alloys Compd. 398, 184 (2005).

${ }^{35}$ S. Karamat, S. Mahmood, J. Lin, Z. Pan, P. Lee, T. Tan, S. Springham, R. Ramanujan and R. Rawat, Structural, optical and magnetic properties of $(\mathrm{ZnO}) 1-\mathrm{x}(\mathrm{MnO} 2) \mathrm{x}$ thin films deposited at room temperature, Appl. Surf. Sci. 254, 7285 (2008).

${ }^{36}$ A. Ahlawat, V. Sathe, V. Reddy and A. Gupta, Mossbauer, Raman and X-ray diffraction studies of superparamagnetic NiFe 204 nanoparticles prepared by sol-gel auto-combustion method, $J$. Magn. Magn. Mater. 323, 2049 (2011).

${ }^{37}$ A. Khorsand Zak, W. H. Abd. Majid, M. E. Abrishami and R. Yousefi, X-ray analysis of $\mathrm{ZnO}$ nanoparticles by Williamson-Hall and size-strain plot methods, Solid State Sci. 13, 251 (2011).

${ }^{38}$ E. Pervaiz and I. Gul, Structural electrical and magnetic studies of $\mathrm{Gd} 3+$ doped cobalt ferrite nanoparticles, Int. J. Curr. Eng. Technol. 2, 377 (2012).

${ }^{39}$ J. Peng, M. Hojamberdiev, Y. Xu, B. Cao, J. Wang and H. Wu, Hydrothermal synthesis and magnetic properties of gadoliniumdoped $\mathrm{CoFe} 2 \mathrm{O} 4$ nanoparticles, J. Magn. Magn. Mater. 323, 133 (2011).

${ }^{40}$ R. Rai, S. Sharma, R. Rani, M. Valente and A. L. Kholkin, Influence of $\mathrm{GdFeO} 3$ addition on the physical properties of $\mathrm{NaKNbO} 3$ lead free ferroelectric ceramics, Mater. Lett. 65, 2703 (2011).

${ }^{41}$ R. K. Mishra, D. K. Pradhan, R. N. P. Choudhary and A. Banerjee, Effect of yttrium on improvement of dielectric properties and magnetic switching behavior in $\mathrm{BiFeO} 3$, J. Phys. Condens. Matter 20, 045218 (2008).

${ }^{42}$ R. Rai, M. Valente, A. K. Shukla, S. Sharma and A. L. Kholkin, Dielectric and magnetic properties of $\mathrm{Ba}-$, La-and $\mathrm{Pb}$-doped 
Bi0.8Gd0.1M0.1Fe0.9Ti0.1O3 perovskite ceramics, J. $A d v$. Dielectr. 4, 1450010 (2014).

${ }^{43}$ Z. Branković, K. Đuriš, A. Radojković, S. Bernik, Z. Jagličić, M. Jagodič, K. Vojisavljevic and G. Branković, Magnetic properties of doped $\mathrm{LaMnO} 3$ ceramics obtained by a polymerizable complex method, J. Sol-Gel Sci. Technol. 55, 311 (2010).

${ }^{44}$ J. Wang, J. Neaton, H. Zheng, V. Nagarajan, S. Ogale, B. Liu, D. Viehland, V. Vaithyanathan, D. Schlom and U. Waghmare, Epitaxial $\mathrm{BiFeO} 3$ multiferroic thin film heterostructures, Science 299, 1719 (2003).

${ }^{45}$ M. M. Kumar, V. Palkar, K. Srinivas and S. Suryanarayana, Ferroelectricity in a pure $\mathrm{BiFeO} 3$ ceramic, Appl. Phys. Lett. 76, 2764 (2000).
${ }^{46}$ J. Rani, K. Yadav and S. Prakash, Dielectric and magnetic properties of xCoFe2O4-(1-x) $[0.5 \mathrm{Ba}(\mathrm{Zr} 0.2 \mathrm{Ti} 0.8) \mathrm{O} 3-0.5(\mathrm{Ba} 0.7 \mathrm{Ca} 0.3)$ TiO3] composites, Mater. Res. Bull. 60, 367 (2014).

${ }^{47}$ D. Tzankov, D. Kovacheva, K. Krezhov and M. Mikhov, Magnetic and transport properties of $\mathrm{Bi0} .5 \mathrm{Ca} 0.5 \mathrm{FexMn} 1-\mathrm{xO} 3(0 \leq \mathrm{x} \leq$ 0.6), J. Phys.: Condens. Matter 17, 4319 (2005).

${ }^{48}$ P. Joy, C. R. Sankar and S. Date, The limiting value of $x$ in the ferromagnetic compositions La1 - xMnO3, J. Phys.: Condens. Matter 14, L663 (2002).

${ }^{49}$ L. Bezmaternykh, E. Kolesnikova, E. Eremin, S. Sofronova, N. Volkov and M. Molokeev, Field-temperature evolution of antiferromagnetic phases in ludvigites Ni3-xMnxBO5, preprint (2014), arXiv:1401.2351. 